\title{
A (DES)IGUALDADE DE GÊNERO NO MERCADO DE TRABALHO: Uma Questão de Direitos Humanos
}

\author{
Suzéte da Silva Reis \\ Autora correspondente. Universidade de Santa Cruz do Sul - Unisc. Avenida \\ Independência, 2293 -Universitário. Santa Cruz do Sul/RS, Brasil. CEP 96810-016. \\ http://lattes.cnpq.br/0526411653933592. https://orcid.org/0000-0001-8820-6385. \\ sreis@unisc.br \\ Priscila de Freitas \\ Universidade de Santa Cruz do Sul - Unisc. Santa Cruz do Sul/RS, Brasil.
}

RESUMO

Os textos constitucionais dos Estados Democráticos asseguram a igualdade de gênero em todos os âmbitos. Do mesmo modo, as Convenções da Organização das Nações Unidas e da Organização Internacional do Trabalho tratam da temática e estabelecem que os Estados signatários adotem ações e estratégias para promover a igualdade de gênero. Apesar dos avanços em termos legislativos, entretanto, a desigualdade de gênero persiste no âmbito do mercado de trabalho, o que representa uma afronta aos direitos humanos e fundamentais. Verifica-se, na esfera laboral, que o princípio da isonomia salarial não é respeitado, pois as mulheres, com o mesmo nível de escolaridade e desempenhando as mesmas funções ainda recebem remuneração menor que a dos homens nas mesmas condições. Além disso, outras formas de discriminação e de tratamento desigual são verificadas constantemente, o que representa uma violação aos direitos humanos. O objetivo do presente trabalho é analisar os principais instrumentos que asseguram a igualdade de gênero, bem como os fatores que contribuem para a perpetuação da desigualdade. Para tanto, o trabalho está dividido em três seções, iniciando pela reflexão acerca dos direitos humanos e a igualdade de gênero. Em seguida, tratará de um dos fatores que contribuem para a persistência da desigualdade salarial, que é o trabalho infantil doméstico de meninas e, ao final, apresenta algumas reflexões sobre a necessidade da superação da desigualdade de gênero. Para realização do presente emprega-se o método de abordagem dedutivo e o método de procedimento analítico, com técnica de pesquisa bibliográfica e documental.

Palavras-chave: Direitos humanos; igualdade de gênero; isonomia salarial; mercado de trabalho.

GENDER (IN)EQUALITY IN THE LABOR MARKET: A MATTER OF HUMAN RIGHTS

ABSTRACT

The Democratic States constitucional texts ensure the gender equality in all areas. In the same way, the United $\mathrm{Na}$ tions and International Labour Organization Conventions, deal with the theme and establish the signatories States adopt strategies and actions to promote the gender equality. However, despite advances in legislative terms, the gender inequality persists in the labor market, which is an affront to human and fundamental rights. It appears, in the workplace, that the wage equality principle is not respected, women with the same education level and performing the same functions still receive less pay than men in the same conditions. Furthermore, other discrimination and unequal treatment forms are constantly checked, what represents human rights violation. The objective of this study is analyze the main instruments to ensure gender equality, as well as factors that contribute to the inequality perpetuation. Thus, the work is divided into three sections, starting with the reflection on the human rights and gender equality. Then, it will address one of the factors contributing to the wage inequality persistence, which is the girls domestic labor and, in the end, it will show some refletions about the need to overcome the gender inequality. For realization of this, is employed deductive approach method and the method of analytical procedure, with bibliographical and documentary research technique.

Keywords: Human rights; gender equality; wage equality; labor market.

Recebido em: 1이일

Aceito em: 20/10/2021 


\section{INTRODUÇÃO}

Parece inadmissível que na segunda década do século 21 as questões de gênero ainda sejam pertinentes e demandem debates. No que diz respeito ao mercado de trabalho, as questões de gênero estão presentes e exigem uma reflexão mais aprofundada, entretanto não apenas no âmbito laboral se observam constantes afrontas aos direitos humanos e aos direitos fundamentais.

A desigualdade salarial entre homens e mulheres aponta para a necessária reflexão acerca da temática. Verifica-se que, apesar de possuírem o mesmo nível de escolaridade e ocuparem os mesmos postos de trabalho, uma parcela significativa de mulheres recebe remuneração inferior à dos homens nas mesmas condições, o que representa um ultraje aos direitos assegurados constitucionalmente.

Por outro lado, o tratamento não isonômico representa uma afronta aos direitos humanos, porquanto homens e mulheres, no exercício das mesmas atividades profissionais, possuindo a mesma formação e desempenhando idênticas funções, devem receber a mesma contrapartida pelo seu trabalho. Além disso, é necessário ter presente que à jornada de trabalho da mulher somam-se as responsabilidades familiares e no âmbito doméstico, configurando a dupla jornada e provocando uma sobrecarga de trabalho.

Historicamente, a responsabilidade pelos cuidados com filhos e afazeres domésticos era incumbência única e exclusiva das mulheres, sem qualquer contraprestação pecuniária. $\mathrm{O}$ caráter econômico dessas atividades ainda não é reconhecido, contudo, ainda que realizadas no âmbito privado e familiar, essas atividades têm repercussão econômica e devem ser consideradas a partir desse viés.

No âmbito laboral, a desigualdade de gênero manifesta-se não apenas na dessemelhança salarial, mas também nas condições de trabalho. A discriminação, as diferentes formas de assédio moral e sexual e a falta de valorização profissional estão presentes nos mais variados segmentos, representando uma afronta aos direitos humanos. A superação da desigualdade demanda ações e políticas voltadas ao enfrentamento dessa temática. Para tanto, é necessário partir da compreensão de que a desigualdade representa uma violação de direitos e que, diante disso, deve ser combatida por todos.

O presente trabalho tem por objetivo, portanto, promover a reflexão acerca do tema, partindo da compreensão de direitos humanos e estabelecendo parâmetros para a compreensão da desigualdade de gênero no âmbito laboral. Para alcançar tal intento, as Convenções das Nações Unidas e da Organização Internacional do Trabalho servirão de base. Os referidos documentos trazem subsídios para o estabelecimento de ações de combate à desigualdade de gênero.

\section{DIREITOS HUMANOS E GÊNERO}

Ao iniciar a abordagem cabe trazer aqui certas introduções acerca de direitos humanos, onde a necessidade que deu origem ao reconhecimento destes ocorreu primeiramente na Europa, tendo em vista que a sociedade burguesa europeia teve a necessidade de obter regulamentações para assegurar suas garantias, conforme é trazido por Pozzoli e Antico $(2011$, p. 6): 


\section{Democracia}

A codificação surge em virtude de um duplo imperativo sócio-econômico (sic): o primeiro era a necessidade de pôr em ordem o caos do direito privado, a fim de garantir a segurança com justiça das expectativas e atender, desta maneira, às necessidades do cálculo econômico-racional de uma economia capitalista em expansão. Enfim, o desenvolvimento de uma política pública de inclusão social, em cumprimento de promessas feitas nas lutas contra os regimes autoritários existentes antes da instituição do Estado de Direito, como conhecemos nos dias atuais. O segundo era fornecer ao Estado, por meio da lei, um instrumento eficaz de intervenção na vida social.

Teles (2006), na mesma linha, faz um retrospecto histórico acerca dos direitos humanos, acentuando que os mesmos tiveram maior reconhecimento após a Revolução Francesa, em 1789. A autora destaca também que, em tal época, houve a proclamação da Declaração dos Direitos do Homem e do Cidadão, na qual em nenhum momento é apontada a igualdade entre os sexos.

Conforme aborda Gorczevski (2009), cronologicamente os direitos humanos dividem-se em quatro gerações. Em um primeiro momento, primeira dimensão, tem-se que os direitos humanos surgiram como resultados de lutas travadas entre os burgueses e o absolutismo. 0 marco dessa dimensão é a Revolução Francesa, ocorrida em 1789, a qual possuía como lema liberdade, igualdade e fraternidade. Tratava-se de direitos de oposição a certas ações do Estado, a não intervenção deste nas relações entre particulares.

Referem-se aos direitos e às liberdades de caráter individual: direito à vida, a uma nacionalidade, à liberdade de opinião, o direito de asilo, à proibição de tortura ou tratamento cruel, desumano ou degradante, à proibição da escravidão, ao direito de propriedade, à inviolabilidade de domicílio, etc. (GORCZEVSKI, 2009, p. 133).

A segunda dimensão dos direitos humanos, conforme destaca o autor, ao contrário dos direitos de primeira dimensão, nesse período são abordados direitos coletivos. Surgiram no fim do século 19 e estavam vinculados ao princípio da igualdade. Tais direitos só poderiam ser usufruídos caso o Estado agisse a fim de proporcionar tais direitos aos cidadãos.

São direitos ao trabalho em condições justas e favoráveis; a proteção contra o desemprego, a assistência contra invalidez, o direito de sindicalização, o direito à educação e cultura, à saúde, à seguridade social, a ter um nível adequado de vida. São direitos que exigem do Estado uma participação, uma ação (GORCZEVSKI, 2009, p. 134).

Já os direitos de terceira dimensão, surgidos no período pós Segunda Guerra Mundial, enquadraram-se no terceiro pilar do lema da Revolução Francesa, qual seja, a fraternidade. Como o período pós-guerra gerou uma comoção em âmbito mundial, tendo em vista as atrocidades ocorridas, passaram a existir direitos que não fossem relacionados com os individuais, ou com a coletividade enquadrada em determinada categoria, mas sim, a todos aqueles que possuem a qualidade de seres humanos.

Estão relacionados com: (a) o direito ao meio ambiente saudável que abrange a preservação da natureza, portanto da biodiversidade; o desenvolvimento sustentável e a qualidade de vida; (b) o direito ao desenvolvimento econômico, o que propicia uma igualdade justa entre todos os povos; (c) o direito à paz, através de uma convivência pacífica e justa entre as nações; a autodeterminação dos povos ao desarmamento mundial, a preserva- 
ção do patrimônio histórico e cultural; (d) o direito à informação, pelo livre acesso a todas as técnicas e meios de comunicação para o conhecimento de toda informação disponível em todos os lugares da Terra (GORCZEVSKI, 2009, p 139).

Gorczevski (2009) faz referência a Wolkmer, que também considera como direitos dessa dimensão os que dizem respeito a questões de gênero, como a dignidade da mulher, além de direitos relacionados com crianças e idosos, direitos dos deficientes mentais e físicos, direitos de minorias e os direitos de personalidade.

Na quarta dimensão dos direitos humanos, surgida no final do século 20, encontramos um período mais relacionado com a globalização, quando ocorre grande crescimento do uso de tecnologias, descobertas científicas e avanços culturais.

São aqueles direitos que se referem à biotecnologia, à bioética e à engenharia genética e que tratam das questões ético-jurídicas relativas ao início, ao desenvolvimento, à conservação e ao fim da vida humana. Dizem respeito à reprodução humana assistida, ao aborto, à eutanásia, às cirurgias intrauterinas, aos transplantes de órgãos, à clonagem, à criação de células-tronco e outros (GORCZEVSKI, 2009, p. 139).

Além das quatro dimensões abordadas, Gorczevski (2009) trata também sobre uma quinta dimensão de direitos humanos, em que são abordados direitos ligados à cibernética.

Com o passar dos anos o reconhecimento dos direitos humanos e a necessidade de positivações de normas, diversos Estados passaram a ter direitos e deveres para com a sociedade por meio de suas Constituições, nas quais deveriam garantir condições mais justas para seus cidadãos. Além da elaboração de Constituições, tornou-se necessária a criação de instrumentos internacionais, como pactos, tratados, convenções para que houvesse maior efetividade de tais direitos (TELES, 2006).

[...] Seu conteúdo aborda temas específicos, como a discriminação racial e contra as muIheres, a proteção dos direitos da criança ou dos trabalhadores. Seus efeitos jurídicos são variáveis conforme a adesão dos Estados signatários e de suas ratificações, bem como a aprovação e a reiteração de seu conteúdo pelos parlamentos nacionais[...] (TELES, 2006, p. 31, grifos próprios).

Correlacionando direitos humanos e gênero, é importante destacar que grandes são os reflexos da desigualdade entre homens e mulheres. Conforme Teles (2006), estudos apontam que existe grande subordinação da população feminina perante a masculina, no âmbito geral, observando-se que, por meio de tais estudos, pode-se apontar causas e buscar possíveis soluções para tal problemática. "[...] Conclui-se que a desigualdade não é fruto do acaso ou da natureza humana. Pelo contrário, a desigualdade social foi criada, inventada e construída pela própria sociedade para atender a interesses de determinados grupos" (TELES, 2006, p. 37).

No âmbito histórico tem-se que, principalmente a partir da década de 70 do século 20, grupos feministas têm buscado dar maior visibilidade às questões relacionadas com discriminações ocorridas contra o gênero, ao longo da História, nos mais diversos setores, mostrando-se importante destacar aqui o âmbito do trabalho, em que, com a divisão do trabalho deu-se espaço para as desigualdades, sendo que as mulheres acabaram excluídas de decisões políticas, religiosas e econômicas, entre outras. Passou-se à divisão de espaços, com os homens 
presentes em espaços públicos e mulheres no privado, no âmbito familiar. Perderam seu poder político sobre sua sexualidade, além de não possuírem voz nas decisões das comunidades (TELES, 2006).

Um documento importante para garantia dos direitos humanos e fundamentais das mulheres é a Convenção sobre a Eliminação de Todas as Formas de Discriminação contra as Mulheres, adotada pela Assembleia Geral das Nações Unidas, de 18 de dezembro de 1979 e promulgada no Brasil pelo Decreto n. 4.316, de 30 de julho de 2002, que em seu artigo 1 을 traz o significado da expressão discriminação contra as mulheres:

Para fins da presente Convenção, a expressão "discriminação contra as mulheres" significa toda distinção, exclusão ou restrição fundada no sexo e que tenha por objetivo ou consequência prejudicar ou destruir o reconhecimento, gozo ou exercício pelas mulheres, independentemente do seu estado civil, com base na igualdade dos homens e das muIheres, dos direitos humanos e liberdades fundamentais nos campos político, econômico, social, cultural e civil ou em qualquer (ONU, 1979).

A partir da Constituição de 1988 a Convenção sobre a Eliminação de Todas as Formas de Discriminação contra as Mulheres passou a ganhar força no Brasil. Segundo Piovesan (2010, p. 203), "a Convenção se fundamenta na dupla obrigação de eliminar a discriminação e de assegurar a igualdade. Trata do princípio da igualdade seja como objeto vinculante, seja como objetivo", visando, de tal forma, não só a eliminar a discriminação contra mulheres, mas também criar medidas a fim de promover a igualdade de gênero.

A Declaração de Pequim e Plataforma de Ação (PFA), de 1995, teve papel extremamente importante no que respeita aos direitos das mulheres. Conforme Vlotti (1995),

identificaram-se doze áreas de preocupação prioritária, a saber: a crescente proporção de mulheres em situação de pobreza (fenômeno que passou a ser conhecido como a feminização da pobreza); a desigualdade no acesso à educação e à capacitação; a desigualdade no acesso aos serviços de saúde; a violência contra a mulher; os efeitos dos conflitos armados sobre a mulher; a desigualdade quanto à participação nas estruturas econômicas, nas atividades produtivas e no acesso a recursos; a desigualdade em relação à participação no poder político e nas instâncias decisórias; a insuficiência de mecanismos institucionais para a promoção do avanço da mulher; as deficiências na promoção e proteção dos direitos da mulher; o tratamento estereotipado dos temas relativos à mulher nos meios de comunicação e a desigualdade de acesso a esses meios; a desigualdade de participação nas decisões sobre o manejo dos recursos naturais e a proteção do meio ambiente e a necessidade de proteção e promoção voltadas especificamente para os direitos da menina.

E, a partir de tais áreas, foram estudadas formas a fim de obter resultados que possam vir a disseminar tais desigualdades, como a adoção de políticas públicas e o empoderamento das mulheres. O Brasil teve participação ativa na Conferência de Pequim.

Não se questionam os avanços no que respeita aos direitos das mulheres no século 20, como se pode constatar. Cabe ressaltar, porém, que a sociedade atual ainda herda muito do sistema patriarcal, o que estimulou, consideravelmente, os preconceitos sobre a população feminina. Desse modo, é imprescindível reforçar as ações para a superação dos preconceitos e de todas as formas de discriminação. 


\section{A DESIGUALDADE DE GÊNERO NO MERCADO DE TRABALHO COMEÇA CEDO: TRABALHO INFANTIL DOMÉSTICO DE MENINAS}

Inúmeros são os fatores que contribuem para a desigualdade salarial no mercado de trabalho. Entre eles, o caráter histórico tem um protagonismo significativo. Desde sempre as mulheres ocuparam um lugar secundário no mundo produtivo. A elas era reservado o espaço doméstico e privado, nos quais as suas incumbências incluíam os cuidados com os filhos e pessoas idosas, bem como os afazeres domésticos. Estas atividades, ainda nos dias atuais, não são consideradas a partir do seu caráter econômico.

Desde os primórdios constata-se que, enquanto os homens desbravavam e conquistavam o mundo, as mulheres ficavam em casa, cuidando de filhos, ordenhando vacas, curando doentes, cozinhando, entre outras tarefas domésticas e, ainda hoje, em alguns lugares, as mulheres continuam fazendo exatamente a mesma coisa. A falta de valorização dispensada ao trabalho da mulher estendia-se a sua vida e a união desses fatores fez com que as atividades desenvolvidas pelas mulheres fossem pouco (ou nada) valorizadas e reconhecidas (MILES, 1989).

A desvalorização das mulheres e do trabalho por elas desenvolvido, especialmente no âmbito doméstico, contribuiu para a sua exploração, em todos os sentidos. A não valorização econômica influenciou o não reconhecimento de direitos e a consequente exploração da mão de obra feminina.

A desvalorização do trabalho doméstico permeia a história das sociedades. A realização das tarefas diárias de cozinhar, limpar, atender às crianças, velhos e doentes recai sobre as mulheres, sem que recebam qualquer contraprestação financeira por isso, pois não se atribui valor econômico a essas atividades. Se, no entanto, este trabalho fosse contabilizado, sua contribuição seria de cerca de 10,3\% do Produto Interno Bruto (PIB) brasileiro para o ano de 2008 (MELO; SABBATO, 2011).

As análises em documentos oficiais revelam a pouca importância dada ao trabalho da mulher, demonstrando que sua variedade, quantidade e significado foram constantemente subestimados, inclusive pelas próprias mulheres, que jamais questionaram a sobrecarga de trabalho - em casa e nas lavouras e campos - que lhe era imposta. Quanto mais duras eram as condições de vida, mais árduo era o trabalho da mulher e mais elas tinham de trabalhar para manter suas famílias. Aos homens, o trabalho destinado também era duro e exaustivo, que exigia o uso da força física muitas vezes até a exaustão, porém eles estavam liberados das atividades domésticas, que era incumbência das mulheres (MILES, 1989).

O marco da dupla jornada de trabalho da mulher, como se observa, inicia-se muito antes da Revolução Industrial, como comumente se crê. A exposição a longas jornadas executando atividade em prol do grupo somava-se à realização das atividades em prol da família. Histórica e culturalmente, o homem estava livre das atividades domésticas.

Nesse sentido, Miles (1989) refere que é um engano afirmar que a mulher trabalhadora seja um problema peculiar do século 20 , pois registros históricos comprovam que as mulheres sempre trabalharam. $O$ trabalho realizado pelas mulheres - limpar peles de caças, por exemplo - era essencial à sobrevivência da tribo, pois sem ele não haveria botas, parkas, depósitos de água e comida, nem tendas, nem caiaques, porém o trabalho feminino nunca conquistou status ou respeito. 


\section{Humanos e \\ Democracia}

E essa situação se reproduz ainda nos dias atuais e, particularmente, no caso do trabaIho infantil doméstico, e os números expressam essa situação: uma parcela significativa das meninas que trabalham são também responsáveis pelos afazeres e atividades domésticas em suas próprias casas.

A perpetuação do ciclo de exploração do trabalho doméstico realizado por meninas encontra suas razões em diversos fatores. Para a Organização Internacional do Trabalho, a erradicação do trabalho infantil doméstico está diretamente relacionada com o combate à pobreza na América Latina e Caribe, assim como a oferta e ampliação de uma educação de qualidade a todas as meninas, meninos e adolescentes (OIT, 2016a).

O trabalho doméstico figura entre as piores formas de trabalho estabelecidas pela Convenção no 182 da Organização Internacional do Trabalho. As estatísticas, contudo, não apontam um elemento que é de extrema relevância: a maior parte dos inquéritos utilizados nas avaliações incluem perguntas apenas sobre o mercado de trabalho remunerado, ou até não remunerado, omitindo assim muito do fardo do trabalho infantil suportado por meninas, a quem são atribuídas, desproporcionalmente, as tarefas domésticas na própria casa.

No Brasil, os números sobre o trabalho infantil doméstico são elevados e causam preocupação. Segundo dados do Fórum Nacional de Prevenção e Erradicação do Trabalho Infantil (FNPETI), no ano de 2011, 258 mil crianças e adolescentes com idade entre 5 e 17 anos estavam ocupados no trabalho infantil doméstico. O número, no entanto, pode ser superior: do total de crianças e adolescentes em situação de trabalho infantil, cerca de 57,7\%, além de trabalharem, ainda eram responsáveis pelas tarefas domésticas em suas próprias casas, realizando atividades como lavar, passar, cozinhar, limpar a casa, cuidar de crianças, entre outras. Ou seja, realizam as mesmas atividades que aqueles que prestam serviços domésticos para outras famílias.

Esses números, entretanto, não refletem totalmente a realidade. A imprecisão dos dados estatísticos acerca do trabalho infantil doméstico decorre do fato de as meninas estarem presentes em formas menos visíveis de trabalho infantil, como o trabalho doméstico que ocorre em residências privadas, e que acabam não sendo incluídos pelas estatísticas. Por outro lado, contribui para a falta de registros estatísticos a falta de consenso sobre o que constituem as tarefas domésticas perigosas, para efeitos de mensuração do trabalho (OIT-IPEC, 2013).

A falta de dados estatísticos acerca do trabalho infantil doméstico e o número de meninas envolvidas na realização dessas atividades configuram-se um fator que dificulta a adoção de medidas protetivas e ações de combate a essa forma de exploração do trabalho infantil, perpetuando-se, com isso, a desvalorização do trabalho da mulher e as desigualdades de gênero que permanecem ao longo da História no mercado de trabalho.

As estatísticas conseguem identificar, com relativo grau de proximidade com a realidade, o número de trabalhadores infantis nos diversos setores econômicos. Em todos eles, o número de meninos é superior ao das meninas, com a exceção do trabalho doméstico, que é "uma forma de trabalho oculta da visão pública e fora da alçada das inspecções de trabalho, o que deixa essas crianças particularmente vulneráveis à exploração e aos maus-tratos" (OIT-IPEC, 2013, p. 7). 
Dados do Fórum Nacional de Prevenção e Erradicação do Trabalho Infantil (FNPETI), revelam que no Brasil mais de $93 \%$ das crianças e adolescentes em situação de trabalho doméstico são meninas, enquanto dados da Organização Internacional do Trabalho (OIT) apontam que a média mundial é de 71\%. Em números, são 241 mil meninas executando tarefas domésticas em casa de terceiros, observando-se que 67\% são meninas negras (FNPETI).

Os dados apresentados pelo FNPETI em 2013 apontavam que mais de 102,6 mil trabaIhadoras domésticas, com idade entre 5 e 17 anos de idade, estão na Região Nordeste. Entre os Estados brasileiros, Minas Gerais é o que registrava o maior número: 31,3 mil trabalhadoras domésticas infantis. Na Região Sudeste são 66,6 mil casos, uma redução de 39,1 mil em relação ao ano de 2009. Os Estados que apresentaram maior percentual de redução foram Roraima, com 68,6\%; Santa Catarina, com 62,2\%; Pernambuco, com 55,9\% e o Distrito Federal, com 73\%. Já os dados da Pesquisa Nacional por Amostra de Domícilio (PNAD) apontava que em 2019, um total de 19,8 milhões de crianças com idade entre 5 e 17 anos realizavam afazeres domésticos ou cuidado com pessoas, sendo que $57,5 \%$ eram meninas.

Esses dados refletem a "crença tradicional de que as tarefas domésticas são inerentes às mulheres e, portanto, empregá-las desde cedo nesta atividade as prepararia para um adequado exercício de sua função como adultas" (OIT, 2016a), o que demonstra a desvalorização das atividades domésticas. A partir do não reconhecimento do valor econômico dessas atividades, ocorre a desvalorização daqueles que as executam.

Melo e Sabbato (2011) destacam que os serviços domésticos, sejam remunerados ou não, se mantêm como uma das formas de trabalho que continuam sendo exercidos pelas mulheres. Segundo os autores, os relatos históricos, desde a Antiguidade, mostram que as atividades domésticas, desenvolvidas por criados e criadas, nunca desapareceu, nem mesmo com o advento da sociedade industrial. Destacam, ainda, que em pleno século 21 , o trabalho doméstico continua sendo desenvolvido por mulheres.

Com a inserção precoce no mercado de trabalho, as meninas enfrentam ainda mais dificuldades para continuarem frequentando a escola. Com isso, outras consequências surgem, como a reprovação, o abandono e a evasão escolar. Com menos qualificação, quando adultas, acabam por se inserir de modo precário no mercado de trabalho ou exercendo atividades informais.

A perpetuação da crença de que o trabalho no âmbito doméstico, familiar ou em casa de terceiros, realizado por meninas, não traz prejuízos, necessita ser superada. Enquanto persistirem as situações de exploração do trabalho de meninas no âmbito doméstico, persistem os fatores que levam à desigualdade de gênero no mercado de trabalho.

É necessário, no entanto, ter presente que não é apenas esse o fator determinante. As questões culturais, sociais, políticas e econômicas são também determinantes para a continuidade da desigualdade de gênero. Diante disso, é preciso reconhecer as situações de desigualdade para, em seguida, estabelecer ações e estratégias para sua superação.

\section{A NECESSÁRIA SUPERAÇÃO DA DESIGUALDADE DE GÊNERO NO ÂMBITO LABORAL}

As estatísticas sobre a desigualdade salarial entre homens e mulheres apontam para dados significativos e que revelam que discriminação de gênero está presente nas relações laborais. Ainda que mais evidente, não é apenas a desigualdade salarial que precisa ser superada. 


\section{Humanos e \\ Democracia}

Segundo dados do Instituto Brasileiro de Geografia e Estatística (IBGE), em 2010 a taxa de atividade das mulheres era de $54,6 \%$, enquanto a taxa de atividade dos homens era de $75,7 \%$. Um dado importante diz respeito à taxa de ocupação das mulheres rurais, que era de $45,5 \%$, enquanto entre as mulheres urbanas a taxa era de $56 \%$. Isso pode indicar que, apesar de realizar atividades no âmbito doméstico, essas atividades não são consideradas com repercussão econômica e, portanto, não são consideradas atividades laborais.

Em relação aos rendimentos, o censo de 2010 realizado pelo IBGE aponta dados importantes para a análise do tema: 30,4\% das mulheres com 16 anos ou mais não tinham nenhum rendimento, enquanto entre os homens o índice era de 19,4\%. Em 2010, 33,7\% das mulheres recebiam até um salário mínimo. Entre os homens, 25,7\% tinham rendimento mensal de até um salário mínimo. De modo geral, de acordo com os dados do censo de 2010, a desigualdade salarial é facilmente perceptível, pois o rendimento médio das mulheres equivale a $67,7 \%$ do rendimento dos homens.

Esses dados revelam que, no âmbito laboral, a desigualdade de gênero permanece, o que gera reflexos nas demais relações sociais e familiares. Isso porque a dependência econômica é, muitas vezes, determinante para a manutenção de outras formas de dependência da mulher em relação aos homens.

O Relatório Mulheres no Trabalho: tendências 2016, publicado pela Organização Internacional do Trabalho, afirma que as mulheres continuam a enfrentar obstáculos significativos no acesso a empregos dignos e que, desde 1995, quando foi realizada a Quarta Conferência Mundial sobre as Mulheres, os progressos alcançados foram apenas marginais, na medida em que a desigualdade entre homens e mulheres persiste.

Nas últimas duas décadas, os significativos progressos alcançados pelas mulheres na educação não se traduziram numa melhoria comparativa na sua situação no trabalho. Em muitas regiões do mundo, as mulheres, comparativamente aos homens, têm mais probabilidades de permanecerem ou virem a ficar desempregadas, têm menos oportunidades de participar no mercado de trabalho e - quando o conseguem - muitas vezes têm de aceitar empregos de qualidade inferior. Os progressos para ultrapassar estes obstáculos têm sido lentos e limitados em algumas regiões do mundo. Ainda que, em muitos dos países as disparidades na participação na população ativa e no emprego se tenham reduzido e mesmo quando as mulheres passam do trabalho familiar não remunerado para o sector dos serviços, a qualidade dos empregos proporcionados às mulheres continua a ser motivo de preocupação (http://www.ilo.org/wcmsp5/groups/public/---dgreports/---dcomm/---publ/documents/publication/wcms_457096.pdf).

Entre os fatores determinantes para a permanência das desigualdades de gênero no mercado de trabalho está a desigual distribuição dos cuidados não remunerados, assim como das tarefas domésticas (http://www.ilo.org/wcmsp5/groups/public/---dgreports/---dcomm/---publ/documents/publication/wcms_457096.pdf). Essa desigualdade também é responsável pela sobrecarga de trabalho a que estão expostas as mulheres. Além da jornada de, em média, oito horas diárias, os cuidados e os afazeres domésticos continuam sendo responsabilidade das mulheres. Desse modo, há um acréscimo na sua jornada diária, contudo por essas atividades realizadas no âmbito doméstico e familiar não há uma contrapartida econômica. 


\section{Humanos e \\ Democracia}

A Organização Internacional do Trabalho, desde muito tempo demonstra preocupação com a temática. A Convenção no 100, adotada em 29 de junho de 1951 e ratificada pelo Brasil pelo Decreto Legislativo n. 24, de 29 de maio de 1956, versa sobre a igualdade de remuneração de homens e mulheres por trabalho de igual valor.

O artigo 10 da referida Convenção estabelece que se entende por remuneração o salário ou o tratamento ordinário, de base ou mínimo, e todas as demais vantagens, pagas direta ou indiretamente, em espécie ou in natura, pelo empregador. $\mathrm{O}$ artigo 2 o estabelece que os Estados-membros deverão incentivar e assegurar a aplicação do princípio da igualdade de remuneração a todos os trabalhadores e trabalhadoras pela realização de um trabalho de igual valor.

Posteriormente, a Convenção no 156, adotada em 23 de junho de $1981,{ }^{1}$ trata sobre os Trabalhadores e Trabalhadoras com Responsabilidades Familiares. $\mathrm{O}$ artigo 10 refere que a mesma se aplica a trabalhadores e trabalhadoras com responsabilidades em relação aos filhos e outros membros da família, quando essas responsabilidades restringirem a possibilidade de se prepararem para uma atividade econômica, incluindo-se tanto o ingresso quanto a participação ou progressão. Por outro lado, o artigo 8 o refere que as responsabilidades familiares não devem constituir motivo válido para a extinção do contrato de trabalho.

Para alcançar tal fim, os Estados deverão adotar medidas efetivas para assegurar que os trabalhadores e trabalhadoras com responsabilidades familiares tenham acesso ao mercado de trabalho, bem como a garantia do tratamento não discriminatório em razão dessas responsabilidades.

A Recomendação no 165, sobre a Igualdade de Oportunidades e de Tratamento entre Trabalhadores e Trabalhadoras com Responsabilidades Familiares, também adotada em 23 de junho de 1981, reitera sua aplicação a todos os ramos da atividade econômica, assim como a todas as categorias de trabalhadores e trabalhadoras, possibilitando que as suas disposições sejam aplicadas por leis, regulamentos, contratos coletivos, laudos arbitrais, decisões judiciais ou por qualquer meio adequado e compatível com a prática e as condições de cada Estado-parte.

A Organização Internacional do Trabalho possui outras Convenções que versam sobre igualdade de gênero: Convenção no 3 sobre a proteção à maternidade, de 1919; Convenção no 41 sobre o trabalho noturno das mulheres, de 1934; Convenção no 45 sobre o trabalho subterrâneo de mulheres, de 1935; Convenção no 89 sobre o trabalho noturno (mulheres), de 1948 e Protocolo, de 1990; Convenção no 103 sobre a proteção à maternidade (revisada), de 1952; Convenção no 100 sobre a igualdade de remuneração, de 1951; Convenção no 111 sobre a discriminação (emprego e ocupação), de 1958; Convenção no 156 sobre os trabalhadores com responsabilidades familiares, de 1981; Convenção no 171 sobre o trabalho noturno, de 1990; Convenção no 183 sobre a proteção à maternidade (revisada), de 2000 e Convenção no 189 sobre trabalho decente para trabalhadoras/es domésticos/as, de $2011{ }^{2}$

\footnotetext{
A Convenção no 156 da Organização Internacional do Trabalho não foi ratificada pelo Brasil.

2 O Brasil não ratificou a Convenção n. 03, sobre a Proteção à maternidade; a Convenção n. 89 - Trabalho noturno (mulheres), de 1948; Convenção n.100 - Igualdade de remuneração, de 1951; Convenção n.103 - Proteção à maternidade, de 1952; Convenção n. 111 - Discriminação no emprego e na ocupação, de 1958; Convenção n.171 - Trabalho noturno, de 1990
} 
Todas essas Convenções trazem subsídios para a superação da desigualdade de gênero e para a garantia dos direitos das mulheres trabalhadoras. A ratificação desses instrumentos, portanto, é o primeiro passo para a promoção da igualdade de oportunidades e de tratamento no âmbito laboral. Conforme as condições e especificidades locais e/ou regionais, os Estados deverão adotar ações e estratégias de superação das desigualdades de gênero no mercado de trabalho, assegurando, desse modo, o respeito aos direitos humanos e fundamentais dos trabalhadores e trabalhadoras.

Outras medidas são necessárias e devem ser adotadas no sentido de combater o tratamento desigual entre homens e mulheres no mercado de trabalho. Para tanto, o diagnóstico da realidade é fundamental, pois é a partir do conhecimento acerca da realidade que é possível estabelecer estratégias eficazes de ação.

A desigualdade salarial atinge diretamente os direitos humanos e fundamentais, porque associada à remuneração inferior, as mulheres sofrem com a discriminação e com a dupla jornada de trabalho, fatores que são determinantes para a conquista da sua autonomia. De acordo com o Relatório Anual Socioeconômico da Mulher, a "promoção da autonomia econômica das mulheres passa pela melhoria de sua inserção no mercado de trabalho e de seus rendimentos, e pela distribuição mais equitativa dos afazeres domésticos e das atividades de cuidado" (RELATÓRIO..., 2015, p. 16).

Concluindo, podemos afirmar que a adoção de gênero, ainda enfrentando um processo de construção, em um contexto histórico de redução de políticas sociais que aumenta a sobrecarga das mulheres e as empobrece, confere constante revelação das condições vividas pela população feminina, colocando o desafio de novas práticas sociais e políticas capazes de abrir caminhos de transformação. Gênero ganha mais capacidade transformadora quando se associa à perspectiva feminista. Ao adotar o ponto de vista feminista, gênero reveste-se de mais poder para impulsionar os questionamentos fundamentais a fim de romper com as ideias patriarcais ainda presentes nos dias de hoje (TELES, 2006, p. 61).

Diante disso, é inquestionável a necessidade de superação de toda e qualquer forma de discriminação e de tratamento desigual, a fim de garantir a observância e o respeito aos direitos humanos e fundamentais de homens e de mulheres.

\section{CONCLUSÃO}

Ainda que se constatem avanços em relação à situação das mulheres no mercado de trabalho, a isonomia, conforme assegurada pela Constituição Federal de 1988, bem como pelos demais instrumentos normativos nacionais e internacionais, está longe de ser alcançada. Corriqueiramente, inúmeras afrontas e violações aos direitos humanos e aos direitos fundamentais são verificadas, decorrentes da desigualdade de gênero.

As mulheres enfrentam inúmeros obstáculos para assegurar a igualdade de acesso e permanência no mercado de trabalho. Por outro lado, também são as mulheres que sofrem com a desigualdade salarial e com as condições não isonômicas no mercado de trabalho. A discriminação, a dupla jornada de trabalho e a falta de valorização do trabalho realizado no âmbito doméstico e em prol da família apresentam-se como alguns dos obstáculos que precisam ser superados. 
Se em tempos passados a mulher executava apenas os trabalhos domésticos, sem repercussão econômica, nos dias atuais a situação foi alterada. A mulher ocupa postos remunerados no mercado de trabalho, participando ativamente da vida econômica e produtiva. As condições de trabalho, todavia, particularmente no que diz respeito à remuneração e valorização, ainda não são isonômicas. Isso porque as mulheres, com a mesma escolaridade e desempenhando as mesmas funções, recebem remuneração inferior à dos homens nas mesmas condições.

Isso reflete que a ideia de sociedade patriarcal ainda permanece bastante enraizada. De acordo com essa concepção, cabe ao homem prover o sustento da família, enquanto à mulher é destinado o papel de cuidar da família e das atividades em prol do grupo familiar. Nas sociedades contemporâneas, contudo, as mulheres chefes de família e que, por essa razão, são as responsáveis diretas e, muitas vezes, única, fonte de subsistência, já alcançam um número expressivo, porém a falta de valorização do trabalho das mulheres permanece, assim como a discriminação salarial.

Os fatores que levam ao tratamento não isonômico perpassam diversas questões e demandam ações de superação dessa desigualdade. Homens e mulheres são iguais em direitos e em deveres. As Convenções Internacionais, tanto da Organização das Nações Unidas quanto da Organização Internacional do Trabalho, assim como a Constituição Federal de 1988, asseguram a igualdade de condições e apregoam a superação da discriminação de gênero.

Cabe, portanto, combater toda e qualquer forma de discriminação de gênero no âmbito do mercado de trabalho, sob pena de violação dos direitos humanos e fundamentais.

\section{REFERÊNCIAS}

FNPETI. Fórum Nacional de Erradicação do Trabalho Infantil. Disponível em: http://www.fnpeti.org.br/. Acesso em: 15 dez. 2015.

GORCZEVSKI, Clóvis. Direitos humanos, educação e cidadania: conhecer, educar, praticar. Santa Cruz do Sul: Edunisc, 2009.

MELO, Hildete Pereira de; SABBATO, Alberto Di. Trabalhadoras domésticas: eterna ocupação feminina: até quando? In: BARSTED, Leila Linhares; PITANGUY, Jacqueline (org.). O progresso das mulheres no Brasil 2003-2010. Rio de Janeiro: CEPia; Brasília: ONU Mulheres, 2011.

MILES, Rosalind. A história do mundo pela mulher. Rio de Janeiro: LTC - Livros Técnicos e Científicos Editora, 1989.

OIT. Organização Internacional do Trabalho. O trabalho doméstico remunerado na América Latina e Caribe. Nota 3. Disponível em: http://www.oitbrasil.org.br/sites/default/files/topic/gender/pub/notas_oit_3_559_733.pdf. Acesso em: 14 mar. 2016a.

OIT. Organização Internacional do Trabalho. Relatório mulheres no trabalho: tendências 2016b. Disponível em: http://www.ilo.org/wcmsp5/groups/public/---dgreports/---dcomm/---publ/documents/publication/ wcms_457096.pdf. Acesso em: 15 mar. 2016.

OIT-IPEC. Organização Internacional do Trabalho; Programa Internacional para a Eliminação do Trabalho Infantil. Medir o progresso na luta contra o trabalho infantil - Estimativas e tendências mundiais 2000-2012. Bureau International do Trabalho. Genebra: OIT, 2013.

ONU. Organização das Nações Unidas. Convenção sobre a eliminação de todas as formas de discriminação contra a mulher. 1979. Disponível em http://www.planalto.gov.br/ccivil_03/decreto/2002/D4316.htm. Acesso em: 22 mar. 2016.

PIOVESAN, Flavia. Direitos humanos e o Direito Constitucional Internacional. 11. ed. São Paulo: Saraiva, 2010. POZZOLI, L.; ANTICO, A. A função promocional do direito ao trabalho digno sob a ótica dos direitos humanos. In: AGOSTINHO, L. O. V. de; HERRERA, L. H. M. (org.). Tutela dos Direitos Humanos e Fundamentais: ensaios a partir 
das linhas de pesquisa construção do saber jurídico e função política do direito. Birigui: Boreal Editora, 2011. p. 2-24.

RELATÓRIO ANUAL SOCIOECONÔMICO DA MULHER. 1a Impressão. Brasília: Secretaria de Políticas para as MuIheres, mar. 2015. 181 p. Disponível em: file:///C:/Users/Pessoal/Downloads/Livro\%20RASEAM_completo\%20 (1).pdf. Acesso em: 17 mar. 2016.

TELES, Maria Amélia de Almeida. O que são direitos humanos das mulheres. São Paulo: Brasiliense, 2006.

VLOTTI, Maria Luiza Ribeiro. Apresentação. In: Declaração e Plataforma de Ação da IV Conferência Mundial Sobre a Mulher. Pequim, 1995. Disponível em: http://www.unfpa.org.br/Arquivos/declaracao_beijing.pdf. Acesso em: 27 mar. 2016.

www.ilo.org/wcmsp5/groups/public/---dgreports/---dcomm/---publ/documents/publication/wcms_457096. pdf). Acesso em: 17 mar. 2016. 